\title{
Integration of ergonomics in the prevention policy of a large university hospital
}

Kristien Selis1, Hilde Vanacker2, Veerle Hermans3, Godewina Mylle4, Herman Devriese5 and Kris Kerckhofs6

1Ergonomics Department, IDEWE, Heverlee, Belgium

2/4 Medical Department, IDEWE, Heverlee, Belgium,

3 Vrije Universiteit Brussel, Work Psychology, Brussels, Belgium

5Prevention Department, University Hospital Leuven, Leuven, Belgium,

6Training Department, University Hospital Leuven, Leuven, Belgium

\section{Introduction}

Leuven university hospital employs today more than 8500 people. The prevention policy of the hospital is aimed at allowing every employee to perform his or her job in safe, healthy and ergonomic circumstances. In order to encourage an ergonomic responsibility at all levels in the organisation, an overall, integrated approach was developed nearly 20 years ago. We evaluated this approach.

\section{Approach}

The following steps were included since 1991 : - Development of an ergonomics steering group.

This policy group is composed of a number of board members, heads of department, doctors, as well as representatives from internal an external prevention services and the training and development department. This group outlines the initiatives and activities concerning ergonomics.

- Set up of an ergonomics working group. This group elaborates the guidelines issued by management, by investigating needs and starting initiatives. They bring together different departments based on the concrete projects that have to be developed.

- Integration of ergonomics in the prevention department.
Since the prevention department is involved within the work organisation of the hospital, also ergonomics is integrated. E.g. for new building projects, purchasing new materials, implementing new working methods, work stations, etc. - Ergonomic reference persons per department were created.

They are the point of contact in their department and signal ergonomic problems and/or improvements to the policy. They keep the attention to ergonomic working and more specifically on the prevention of MSD injuries. On site ergonomic projects. We first start with a participatory risk analysis, followed-up by implementing the correct prevention measures: technical changes in work places or work organisation, integration of helping devices and finally workers instructions and training.

A global approach prevents that training at the working place is considered as the only ergonomic practice.

\section{Evaluation of the global integrated approach}

Evaluation of the number of work accidents caused by transfer of patients.

- Subjective survey regarding the occurence of musculoskeletal disorders (MSD) and impact of the ergonomic policy, during the periodic health assessment. 


\section{Results}

Evaluation of the number of work accidents caused by transfer of patients. A significant decrease of the number of work accidents caused by lifting and moving patients by the nursing staff has been found. In view of the large increase $(30 \%)$ of nurses in all these years we have been able to reduce the number of work accidents caused by lifting and moving patients by more than $66 \%$. The absenteeism figures decreased almost $90 \%$.

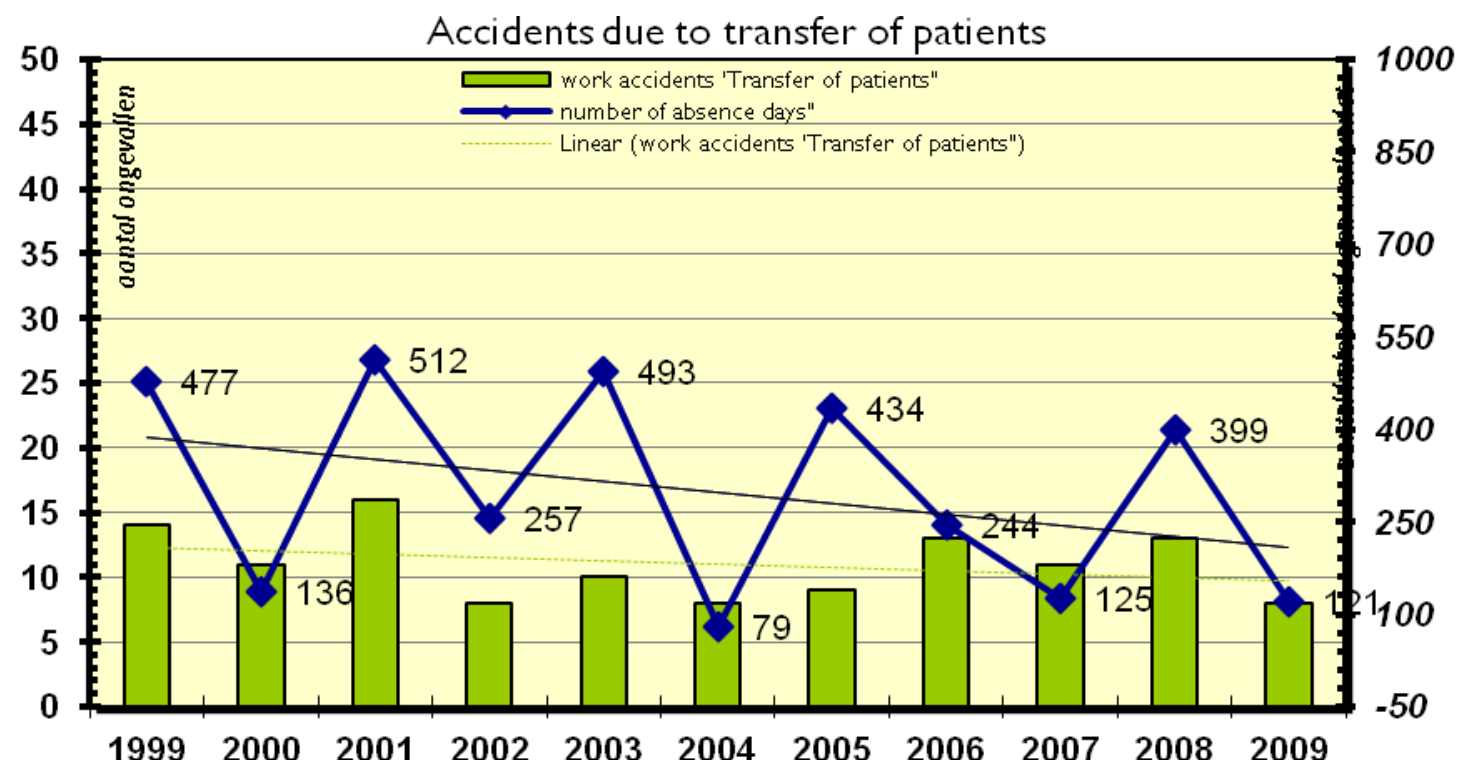

Of course, this only includes accidents on site and not sickness absence due to low back pain or other MSD.

\section{Subjective survey.}

1062 from the 8500 employees were questioned. The following results were obtained:

- $\quad 56,7 \%$ reported MSD. Complaints of low back, neck and shoulders are most common

- A higher prevalence of MSD at administrative staff, nurses, care staff and support services. Lower prevalence of MSD at paramedics, technical staff and doctors.

- $35.2 \%$ reported that the MSD were workrelated, 27.7\% possible work-related and $37.1 \%$ non-work-related. Among younger employees more often work-related complaints $(38 \%$ in $<35$ year olds compared to $21.7 \%$ at $55+$ )

- More than $74 \%$ of the respondents adjusted their workstation and/or work position to avoid or reduce physical load.
- $\quad 70,3 \%$ indicated that they feel well supported by the ergonomic policy.

- $\quad 78 \%$ felt that adequate information or training is given.

- $\quad 77,5 \%$ reported no absenteeism due to their disorders.

\section{Discussion}

A huge decrease in accidents caused by transfer of patients was found. We brought the risk to an acceptably low level. The results of the subjective survey reveal that the ergonomic policy is integrated at all levels. More than $70 \%$ of employees feel well supported by the policy. This result gives us the signal that the awareness and knowledge regarding ergonomics among the employees is sufficient. The fact that $77.5 \%$ continues to perform their work despite their MSD, gives us the signal that the physical demands of the work is acceptable or can be adequately adjusted in function of the MSD. Staff 
have sufficient control capabilities and support to adjust their workstation and/or work position to avoid or reduce physical load.

With the survey we missed the people who were, at the time of the survey, absent because of MSD or other pathologies. The policy has been adjusted to give this group more individual training and follow up. We believe this will reduce the risk of relapse and or will promote reintegration at work. Despite the good results on the work accidents and the good subjective evaluation, there remains the fact that nearly $60 \%$ of the employees reports MSD and that more than $60 \%$ of these are brought in relation with their work. Therefore an ergonomic policy must take a permanent and integral place in the organization.

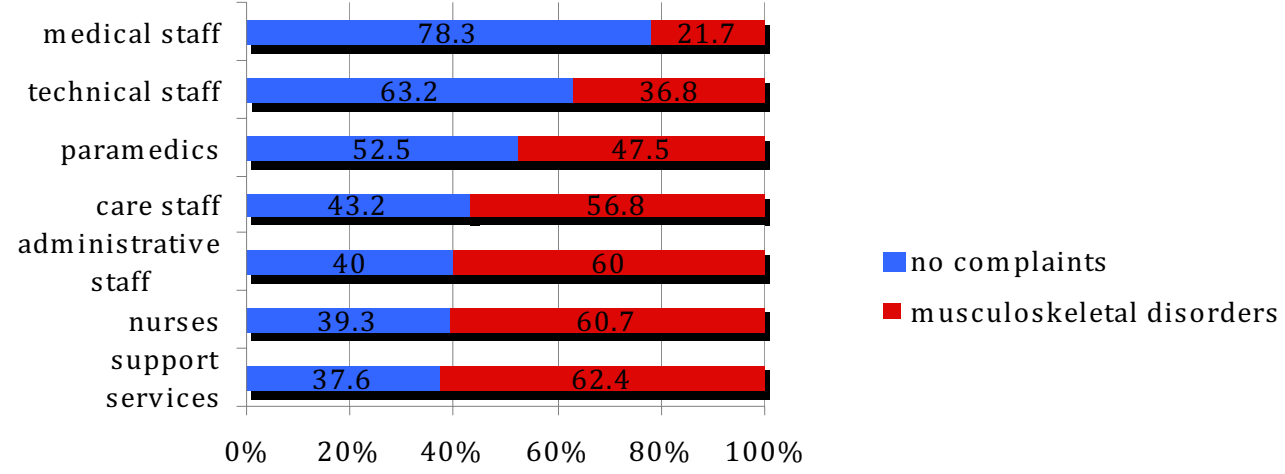

Figure 2 : Percentage of employees with musculoskeletal disorders divided by function

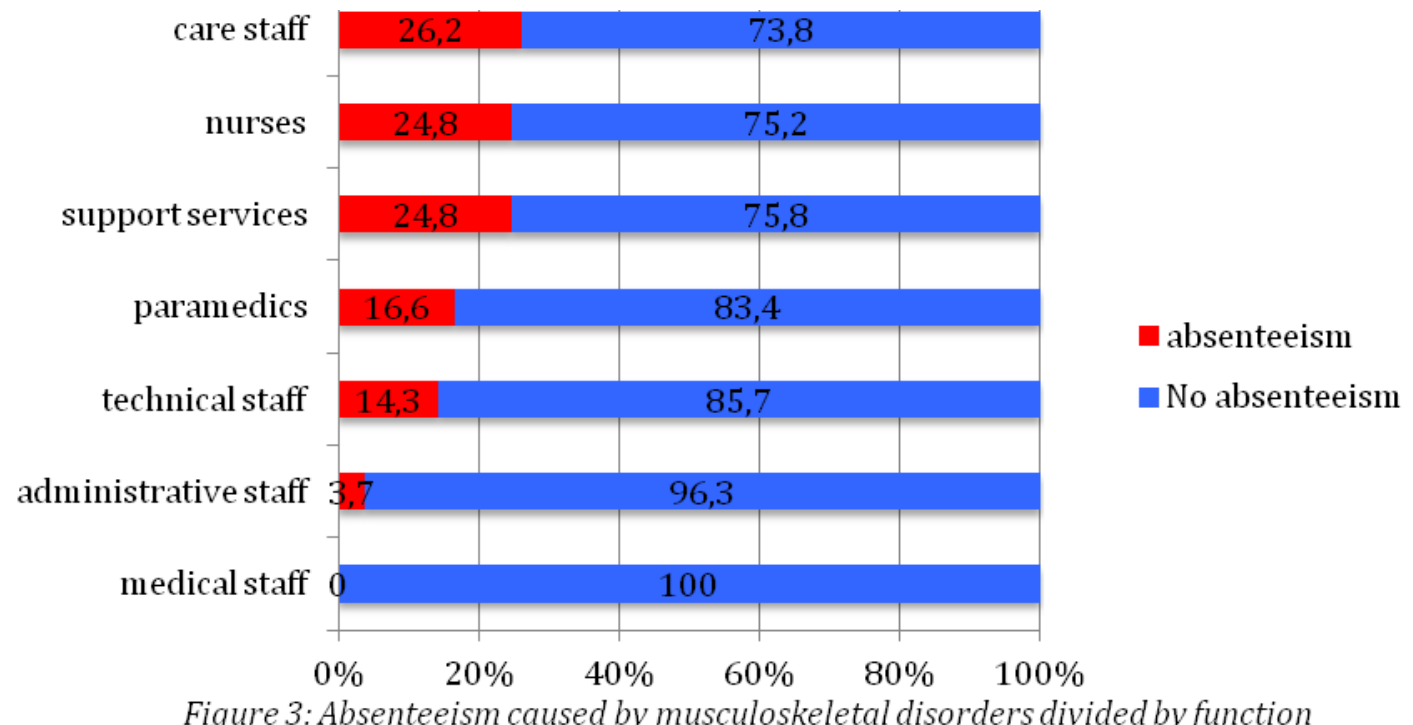

Figure 3: Absenteeism caused by musculoskeletal disorders divided by function 
Figure 4 : Percentage of employees, who adapt their ergonomic situation to prevent physical overload

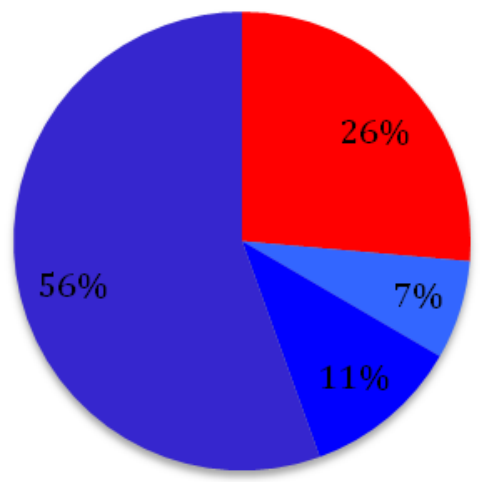

no initiatives

adaption of workstation

- adaption of work position

adaption of work position AND workstation 